\title{
CONCEPÇÕES DOS PROFESSORES COORDENADORES SOBRE ESTUDANTES COM AUTISMO
}

\author{
Cintia Souza Borges de Carvalho ${ }^{1}$ \\ Gabriely Cabestré Amorim²
}

\begin{abstract}
RESUMO: A presente pesquisa analisa as concepções de professores coordenadores (PC) atuantes no Ensino Fundamental (EF) - anos iniciais, sobre a inclusão de estudantes com autismo. Objetivou-se descrever, sob a ótica desses profissionais, as concepções a respeito de estudantes com autismo, refletindo sobre como estas podem influenciar na formação continuada dos professores e, consequentemente, na inclusão destes alunos. Trata-se de pesquisa qualitativa, em que foram realizadas entrevistas durante os meses de setembro e outubro de 2015, com cinco PC responsáveis pelo EF. Os dados indicam que, embora conheçam as definições sobre o autismo, ainda possuem uma visão médica sobre seus estudantes, a qual exerce influência na inclusão no ensino regular, na relação com as famílias e, sobretudo, na formação dos educadores. Assim sendo, considera-se fundamental uma formação sistemática aos PC sob uma perspectiva reflexiva e inclusiva, para que se possa articular o trabalho pedagógico com os professores, possibilitando real inclusão do estudante com autismo.

Palavras-chave: Educação Especial. Inclusão. Autismo. Formação Continuada. Coordenação Pedagógica.
\end{abstract}

\section{CONCEPTIONS OF COORDINATORS TEACHERS ABOUT STUDENTS WITH AUTISM}

ABSTRACT: The present research analyzes the conceptions of coordinating teachers (PC) in Elementary School (EF) - initial years, on the inclusion of students with autism. The objective was to describe, from the perspective of these professionals, the conceptions about students with autism, reflecting on how these can influence the continued formation of the teachers and, consequently, the inclusion of these students. It is a qualitative research in that interviews were conducted during the months of September and October 2015, with five PC responsible for EF. The data indicate that, although they know the definitions about autism, they still have a medical vision about their students, which influences inclusion in regular education, relationships with families and, above all, the education of educators. Thus, it is considered fundamental to systematically train the $P C$ in a reflective and inclusive perspective, so that the pedagogical work can be articulated with the teachers, thus enabling the student to be truly included with autism. Keywords: Special Education. Inclusion. Autism. Continuing Education. Pedagogical

\footnotetext{
${ }^{1}$ Professora dos anos iniciais do Ensino Fundamental na Secretaria da Educação do Estado de São Paulo.

2 Doutoranda em Educação na Universidade Estadual Paulista - UNESP/Marília. E-mail: gcabestre@gmail.com
} 
Coordination.

\section{CONCEPCIONES DE PROFESORES COORDINADORES SOBRE ESTUDIANTES CON AUTISMO}

RESUMEN: La presente investigación analiza las concepciones de profesores coordinadores (PC) actuantes en la Educación Primaria, sobre la inclusión de estudiantes con autismo. Se objetivó describir, bajo la óptica de esos profesionales, las concepciones acerca de estudiantes con autismo, reflexionando sobre cómo éstas pueden influenciar en la formación continuada del profesorado y, consecuentemente, en la inclusión de estos alumnos. Se trata de una investigación cualitativa en la que se realizaron entrevistas durante los meses de septiembre y octubre de 2015, con cinco PC responsables de EF. Los datos indican que, aunque conozcan las definiciones sobre el autismo, todavía poseen una visión médica sobre sus estudiantes, la cual influye en la inclusión en la enseñanza regular, en la relación con las familias y sobre todo en la formación de los educadores. Por lo tanto, se considera fundamental una formación sistemática a los PC desde una perspectiva reflexiva e inclusiva, para que se pueda articular el trabajo pedagógico con los profesores, posibilitando una verdadera inclusión del estudiante con autismo.

Palabras clave: Educación Especial. Inclusión. Autismo. Formación continuada. Coordinación pedagógica.

\section{Introdução}

Desde 2008, a Secretaria de Estado da Educação de São Paulo, considerando as especificidades dos anos iniciais do Ensino Fundamental, passou a contar com um posto de trabalho de professor coordenador - doravante identificado como PC - designado especificamente para exercer a função pedagógica neste segmento, sendo observadas, dentre as suas atribuições, a função de

[...] III- assumir o trabalho de formação continuada, a partir do diagnóstico dos saberes dos professores para garantir situações de estudo e de reflexão sobre a prática pedagógica, estimulando os professores a investirem em seu desenvolvimento profissional;

[...] V- organizar e selecionar materiais adequados às diferentes situações de ensino e de aprendizagem (SÃO PAULO, 2007, art. 2ํ).

Ao assumir o papel de formador de outros formadores, expresso em suas atribuições, tornase fundamental que o PC considere a atual perspectiva de educação para todos, na qual se insere o processo de inclusão das escolas estaduais de ensino de São Paulo. Ela tem como foco a garantia de uma educação eficaz, "em defesa do direito de todos os estudantes de estarem juntos, aprendendo e participando, sem nenhum tipo de discriminação" (BRASIL, 2008, p. 1). Assim sendo, cabe ao PC apoiar o desenvolvimento profissional dos docentes de seu segmento para responderem à crescente 
diversidade na sala de aula, incluindo indiscriminadamente todos os estudantes, ou seja, também aqueles que são público-alvo da Educação Especial - estudantes com deficiência, transtornos globais do desenvolvimento (TGD) e altas habilidades ou superdotação (SÃO PAULO, 2014).

Esse processo é extremamente árduo por diversas circunstâncias, tais como a fragmentação do tempo destinado à formação nas escolas, ou ainda as dificuldades na sistematização dos estudos nas Aulas de Trabalho Pedagógico Coletivo (ATPC), mas em se tratando da inclusão de estudantes com autismo, os desafios com relação à inclusão efetiva e à formação continuada são ainda mais complexos. Primeiramente, essa complexidade se dá, segundo Belisário Filho e Cunha (2010), devido às constantes mudanças nos conceitos de autismo e por ainda ser recente. A contínua profusão de nomenclaturas e a dificuldade de se chegar a um consenso para além das terminologias têm provocado entraves entre profissionais das áreas da educação e saúde na adoção de uma mesma linguagem no que se refere ao autismo (LAGO, 2007). Como resultado desse processo, observa-se que:

[...] a influência dos modelos explicativos sobre o autismo, ao longo da história, determinou as primeiras iniciativas de intervenção no ensino que, entretanto, foram muito específicas e distanciadas daquelas desenvolvidas no meio social inerente à escola como a conhecemos hoje (BRASIL, 1999, p. 8).

Assim sendo, pôde-se perceber que à medida que a sociedade delineava as limitações causadas pelo autismo, gastando grande parte do tempo uma abordagem patológica, clínica, reforçava-se a descrença de que a educação regular de crianças com autismo fosse possível, mediante estas mesmas limitações. Esse "descrédito educacional" do autista foi e ainda é tão marcante na sociedade brasileira que, mesmo com a crescente busca de superação do processo de integração escolar e a implantação da Política Nacional de Educação Especial na Perspectiva da Educação Inclusiva (BRASIL, 2008), continuam a existir diversos centros especializados e substitutivos ao ensino regular destinados especificamente para autistas, baseando-se, em sua grande maioria, em objetivos integradores, assistencialistas e "normalizadores".

Camargo e Bosa (2012) destacam ainda que, nesse contexto de integração e normalização, muitos mitos foram criados, principalmente em relação à impossibilidade do desenvolvimento social do indivíduo com autismo, tardando assim cada vez mais a construção de uma visão inclusiva, em que a educação regular fosse reconhecida como benéfica e viável. Essas dificuldades e inconsistências são tão aparentes, não somente no âmbito educacional, mas também em outras esferas sociais, que tornou-se necessária a criação da Lei no 12.764, de 27 de dezembro de 2012 (BRASIL, 2012), 
estabelecendo especificamente uma política nacional de proteção dos direitos da pessoa com Transtorno do Espectro Autista. Dentre outras propostas e sanções, esse meio legal veda a recusa de matrícula aos autistas e estabelece punição para o gestor escolar ou autoridade competente que pratique esse ato discriminatório, fato necessário, ainda que anos após implementação da Política Nacional de Educação Especial na Perspectiva da Educação Inclusiva. Mediante toda essa problemática, é muito comum que, por parte dos professores, a vivência dos primeiros momentos em contato com esses alunos seja "carregada de sentimento de impotência, angústia e geradora de falsas convicções a respeito da impossibilidade de que a escola e o saber/fazer dos professores possam contribuir para o desenvolvimento daquela criança" (BELISÁRIO FILHO; CUNHA, 2010, p. 22).

Nessa perspectiva, Duk (2006) ressalta a importância do PC, ao afirmar que para que tenham condições de enfrentar esse desafio, os professores "precisam contar com ajuda e apoio em caráter permanente que possibilitem a participação contínua em atividades de formação bem como de assessoramento ao desenvolvimento da prática docente (DUK, 2006, p. 15). A autora ressalta ainda que esses momentos de formação dependam, sobremaneira, da cultura escolar, ou seja, do "conjunto de crenças e convicções básicas mantidas por professore(a)s e comunidade escolar em relação ao ensino, à aprendizagem dos alunos e ao funcionamento da escola" (DUK, 2006, p. 116), fatores estes que se relacionam à atuação da equipe gestora, mas sobretudo, do PC frente às intervenções pedagógicas.

Vale ressaltar que, embora a aprendizagem do estudante com autismo seja diferente entre si, estudos apontam benefícios quando há inclusão efetiva na classe comum (BERETA; VIANA, 2014; CAMARGO, 2007; SERRA, 2004). Porém, muitos mitos, principalmente com relação aos comportamentos estereotipados, ainda permanecem, fazendo-se necessário então investir na formação continuada, considerando as possibilidades de aprendizagem e não a visão clínica dos transtornos.

Nesse contexto, diversos questionamentos nos inquietam: quais conceitos o PC possui com relação ao autismo? Existem fatos baseados no senso comum a respeito do comportamento do aluno com autismo que ainda permeiam a prática desses profissionais? De que forma essas reflexões e posturas influenciam os docentes durante as ações de formação continuada? Considerando a relevância desses questionamentos para a efetiva inclusão do estudante com autismo, justifica-se esta pesquisa, sabendo que a cada reflexão aqui levantada, novas possibilidades e novas dúvidas são colocadas, o que é próprio do processo de construção da aprendizagem. 
Espera-se assim que este trabalho possa contribuir para o estabelecimento de novas convicções referentes a esses estudantes e, sobretudo, de novas questões que possam mobilizar a busca de práticas de formação continuada que levem a uma real inclusão acreditada de que "incluir significa oferecer aos estudantes uma escola adaptada as suas diferenças individuais, que contemple suas necessidades educativas especiais, de fato e não só na promessa ou no texto constitucional" (PAULA, 2004, p. 13). Este estudo tem, portanto, como objetivo geral descrever sob a ótica dos PC atuantes nos anos iniciais do ensino fundamental as concepções a respeito da inclusão de estudantes com autismo, trazendo como objetivo específico refletir sobre como estas ideias e concepções podem influenciar na formação continuada dos professores e, consequentemente, na inclusão destes estudantes.

\section{Caminho metodológico percorrido}

A pesquisa foi realizada em 2015 , com professores coordenadores atuantes em escolas estaduais de São Paulo, jurisdicionadas à Diretoria de Ensino da Região de Itaquaquecetuba. Essa Diretoria atende dois municípios da grande São Paulo e conta com 60 escolas estaduais nos níveis de Ensino Fundamental - Anos Iniciais e Finais, e Ensino Médio, sendo uma delas de ensino integral e um Centro Estadual de Educação de Jovens e Adultos - CEEJA. Cumpre saber ainda que, de acordo com levantamento de agosto de 2015, do Centro de Informações Educacionais da Diretoria de Ensino, essas escolas totalizavam 57.332 estudantes matriculados, dos quais 827 são do Público-Alvo da Educação Especial (PAEE).

A Diretoria de Ensino possuía, no ano da pesquisa, nove PC atuantes nos anos iniciais, sendo que todos foram convidados a participar da pesquisa, porém cinco aceitaram responder a entrevista. Foi utilizado, para a coleta de dados, um roteiro de entrevista semiestruturada (MANZINI, 2003) que abordou questões sobre experiência profissional e formação dos participantes, visando delinear um perfil do grupo, além das questões referentes ao conhecimento e experiência que os participantes já tiveram com o autismo, bem como suas concepções a respeito deste transtorno, a inclusão e o atendimento educacional especializado a ser ofertado a estes estudantes, a relação com suas famílias e o papel dos professores coordenadores frente à formação dos docentes para atuação pedagógica nesta área.

As entrevistas foram realizadas individualmente, nos meses de setembro e outubro de 2015, nas próprias unidades escolares onde os PC atuavam em dia e horário definidos pelos participantes. $\mathrm{O}$ 
registro dos dados ocorreu por meio da gravação de áudio. Os participantes foram identificados com as siglas PC1, PC2, PC3, PC4 e PC5.

Caracterizada como uma pesquisa qualitativa, o tratamento dos dados coletados foi realizado pela análise de conteúdo (BARDIN, 2011), sendo categorizadas como: 1) Concepções sobre autismo 2) Atendimento educacional aos estudantes com autismo; 3) Relação entre escola e família; 4) Papel do professor coordenador frente à inclusão de estudantes com autismo. A pesquisa está vinculada ao Programa Redefor Educação Especial e Inclusiva intitulada "Rede de educação inclusiva: Formação de Professores nos âmbitos de Pesquisa, Ensino e Extensão", aprovada pelo Comitê de Ética em Pesquisa (CAAE), da Faculdade de Ciências e Tecnologia (FCT), UNESP, campus de Presidente Prudente, SP, sob o no 26341614.3.0000.5402, cujo parecer no 632.386 é datado de 09 de maio de 2014.

\section{Resultados e discussões}

Inicialmente, apresentamos um sucinto perfil do grupo de PC entrevistados, detalhado no Quadro 1.

Quadro 1 - Perfil dos entrevistados

\begin{tabular}{|c|c|c|l|c|l|}
\hline Professor & Sexo & Idade & $\begin{array}{c}\text { Formação } \\
\text { Inicial }\end{array}$ & $\begin{array}{c}\text { Experiência } \\
\text { Coordenação } \\
\text { Pedagógica }\end{array}$ & Atuante no segmento \\
\hline PC1 & Feminino & 42 & História & 10 anos & $\begin{array}{l}\text { Ensino Fundamental - Anos Iniciais e } \\
\text { Finais }\end{array}$ \\
\hline PC2 & Feminino & 39 & História & 11 anos & Ensino Fundamental - Anos Iniciais \\
\hline PC3 & Feminino & 32 & $\begin{array}{l}\text { Artes } \\
\text { Plásticas }\end{array}$ & 06 anos & $\begin{array}{l}\text { Ensino Fundamental - Anos Iniciais e } \\
\text { Finais; Ensino Médio }\end{array}$ \\
\hline PC4 & Feminino & 52 & Pedagogia & 20 anos & Ensino Fundamental - Anos Iniciais \\
\hline PC5 & Masculino & 45 & Pedagogia & 05 anos & Ensino Fundamental - Anos Iniciais \\
\hline
\end{tabular}

Fonte: Os próprios autores.

Nenhum dos entrevistados concluiu cursos na área de Educação Especial, a PC4 afirmou ter iniciado um curso de Libras, porém, não finalizou, enquanto a PC1 mencionou ter participado de seminários de curta duração na área de deficiência auditiva, oferecidos pelo Núcleo de Apoio Pedagógico Especializado - CAPE, órgão da Secretaria de Estado da Educação de São Paulo, pois a escola onde atuava anteriormente possuía Sala de Recursos nesta área. Somente PC1 e PC2 tiveram ou ainda têm contato com autistas - em ambos os casos, estudantes incluídos no ensino regular. A PC1 
destaca que a experiência tem sido uma novidade, porém, que os alunos PAEE, em geral, estão tão integrados na escola em que atua que não há distinção imediata dos demais. A PC2 relata que, no primeiro momento, foi assustador, devido à falta de experiência, porém, enfatiza que buscou informações e que hoje já não acredita ser "um bicho de sete cabeças".

\section{Concepções sobre autismo}

As primeiras impressões relatadas pelos participantes acerca das concepções do que é o autismo e como ele se apresenta, centram-se, em sua totalidade, em uma ideia de enclausuramento em um mundo próprio, de total isolamento, reserva e limitação, como observado nos relatos de PC1 e PC4.

Diz que eles ficam isolados, que a pessoa fica muito na dela [...] O autismo, a ideia que eu tenho dele... é a de que ele [o autista] vive mais no mundinho dele, que é centrado, limitado [...] (PC1, 2015).

Eu acredito que é aquele estudante que fica no mundo dele, não é? Não se relacionará nunca com as outras crianças [...] (PC4, 2015).

Na sequência, a PC3 e o PC5 enfatizaram a ausência ou extrema dificuldade na comunicação dos autistas. Já as PC1 e PC2 retrataram as persistentes restrições quanto ao contato físico. Em todas as citações, os entrevistados demonstraram acreditar que esses comportamentos são voluntários, ou seja, uma opção ou escolha para o autista, como relatado a seguir.

Ele [o autista] não quer ter contato físico (PC1, 2015).

Eles [os estudantes autistas] evitam aproximação (PC2, 2015).

Ele preferia assim, sempre ficava reservado e quieto (PC3, 2015).

Eles não são de muita conversa (PC5, 2015).

Tratando ainda da definição do autismo, a PC2 enfatizou que existem momentos de agressividade e hiperatividade, enquanto as PC1 e PC4 destacaram a presença dos comportamentos estereotipados, ainda destacando, mesmo que implicitamente, certa voluntariedade nestes atos, como se pode observar em seus relatos.

Ela [a aluna autista] faz movimentos [agita as mãos] pra chamar a nossa atenção só pra ela (PC1, 2015).

[...] e tem aquele estudante [autista] que quer chamar a atenção, sabe? Eu vejo assim, que eles têm momentos de agressividade, de hiperatividade, parece que eles ficam agressivos assim, do nada (PC2, 2015).

Ele faz muito movimento, assim, com as mãos [bate as mãos uma na outra] (PC4, 2015). 
Essas impressões foram acrescidas ainda de uma imensa insegurança e receio por parte de todos os PC entrevistados ao tentar discorrer sobre o que é o autismo. A maior parte iniciou a fala dizendo que essa é uma questão muito difícil, que não há como defini-la precisamente ou alegando que não possuíam experiência ou conhecimento suficiente para afirmar com certeza. Faziam pausas durante a fala e buscavam a confirmação da entrevistadora ("não é isso?", "estou certa?", "eu acho que é assim...").

Segundo Gadotti (2001, p. 3), "o projeto da escola depende, sobretudo, da ousadia de seus agentes"; assim sendo, faz-se necessário refletir se, de fato, esses professores coordenadores terão a "ousadia" esperada para construir um espaço pedagógico e formativo, de fato inclusivo para os estudantes com autismo. Nessa perspectiva, podemos perceber que a maioria dos entrevistados possui as principais informações associadas ao conceito atual do TEA, ou seja, reconhecem os prejuízos na comunicação e interação social, além dos padrões restritos e repetitivos de comportamento. Conforme a definição adotada por esta pesquisa, pode-se perceber que ainda persiste uma visão bastante clínica e epidemiológica, "que "encaixa" as pessoas em transtornos e diagnósticos, como se todos os recebedores daquele laudo médico fossem acometidos por uma doença, um problema com diversas características iguais" (LOPES, 2011, p. 9), como no relato de PC2.

Quando se fala em autismo, nós achamos que é tudo um só, a gente desconhece aquela classificação, não é? Nível I, nível II, nível III... [refere-se ao Manual de Diagnóstico e Estatística dos Transtornos Mentais (DSM V) ${ }^{3}$ ]. Eu estou conhecendo hoje porque tem uma professora daqui, que o filho dela é autista e ela me passa as informações. Mas, antes eu desconhecia que têm diferenças entre eles, eu não sabia disso! Pra mim era tudo o mesmo grau, a mesma coisa, mas ela estava me explicando... Tem pessoas que nem apresentam assim, "fisicamente" que tem autismo, mas têm várias características e tudo isso eu nem sabia! (PC2, 2015).

A PC1, que possui contato recente com uma estudante com autismo regularmente matriculada em sua Unidade Escolar relata que

Ela não tem esta questão da distância, como eu lia, como eu acompanhei, de ficar naquele mundinho dela, ela tem outras dificuldades... Muito pelo

\footnotetext{
${ }^{3}$ American Psychiatric Association. Manual diagnóstico e estatístico de transtornos mentais: DSM-5. Tradução de Maria Inês Corrêa Nascimento et al. 5 ed. Porto Alegre: Artmed, 2014.
} 
contrário, toda pessoa que ela gosta, que ela vê sempre, aquela que recebeu ela primeiro, que tem acompanhado ela aqui na escola, ela tem um contato maior, então ela gosta de pegar, ela gosta de conversar, [...] então, eu até observo... Então que, talvez, ela nem seria autista, nesta situação, talvez [...] (PC1, 2015).

Essa perspectiva se traduz diretamente na maneira com que a escola acolhe a criança com autismo, "muito mais enxergando-a como ela deveria ser, de acordo com padrões pré-estabelecidos e esperados, do que a vendo e respeitando em suas possibilidades e limites" (LOPES, 2011, p. 10).

Além disso, essa centralização no prognóstico médico traz à tona outra dificuldade, os entrevistados demonstram acreditar nas limitações do autista como algo voluntário, permanente e não passível de evolução ou mudanças. Nenhum dos relatos se traduziu em detalhar as dificuldades do estudante com autismo, enfatizando as suas possibilidades, potencialidades e especificidades, para além do diagnóstico recebido, o que pode dificultar ou até inviabilizar abordagens pedagógicas possíveis de serem realizadas no ensino regular. De acordo com Lopes (2011, p. 10): “O diagnóstico de autismo tende a reduzir as expectativas dos professores sobre o aprendizado da criança ou do adolescente, [...] praticamente inviabiliza o reconhecimento daquilo que cada sujeito efetivamente pode alcançar em sua vivência escolar

\section{Atendimento educacional aos estudantes com autismo}

Com relação ao atendimento educacional a ser ofertado aos estudantes com autismo, todos os entrevistados fizeram menção, de alguma forma, à inclusão na rede regular de ensino como ação pedagógica principal. Todavia, pode-se perceber que as abordagens dadas à inclusão escolar não se traduzem em aplicação prática, mas somente de discurso, já que não houve ênfase na totalidade dos reais benefícios do processo inclusivo, como observado no relato de PC1.

\footnotetext{
$\mathrm{Na}$ sala de aula, eu acho que ele [o autista] tem que estar inserido, de acordo... Tem que estar inserido! [...] A partir do momento que a lei foi lançada e que vieram todos, eles não apareceram do nada, não é? Não fez um "pirlipimpim" e todo mundo apareceu, não! Eles estavam aí, só que cada um no seu cantinho, não é? E agora que todos têm oportunidade, a escola não pode falar não pra eles dentro da própria escola, entende? Tem que fazer a matrícula! Então, não é que eles apareceram, eles já existiam e agora eles estão conosco! E eu sou a favor, acho que tem que incluir, sim (PC1, 2015).
}

Verificou-se, por exemplo, nas afirmações da PC1, uma preocupação em apontar como um caminho a inclusão do autista no ensino regular, contudo, atrelada à questão da obrigatoriedade legal 
de matrícula. Nesse contexto, a abordagem vai ao encontro da afirmação de Lago (2007, p. 22), destacando que "somente a legislação não é suficiente para garantir uma prática inclusiva nas escolas, que, historicamente, desenvolvem uma rotina que se pode chamar de excludente". A PC2 traz a questão da inclusão escolar, porém, abordando outro viés.

\begin{abstract}
Na escola, quando incluímos, tem que ter carinho, atenção, olhar no olho dele [do estudante autista], acalmar... Ser bem calmo tem que ser bem calmo mesmo [enfatiza este trecho], sempre com tranquilidade, a gente tem que passar tranquilidade e segurança pra esses estudantes. É um processo de conquista, não é? E quando a gente conversa com ele, a primeira coisa que a gente fala é que ele está bonito, não é? Que ele está cheiroso... Pra aumentar a autoestima dele... Ele ficou assim tão acessível quando nós começamos a... aumentar a autoestima dele, que agora todo dia ele passa aqui e fala: "tchau"! (PC2, 2015).
\end{abstract}

Nesse caso, percebe-se que há um reducionismo do processo inclusivo, associando-o somente às questões sociais: seriam os autistas, nesta perspectiva, crianças que necessitariam somente de "amor" para obter sucesso em sua escolarização. Essa visão é associada à crença de que o estudante com autismo está incluído na escola somente para socializar, devendo assim somente ser preparado para circular socialmente no meio de forma adequada. Concordamos com Camargo e Bosa (2012), que acredita que ao

[...] proporcionar aos estudantes com autismo oportunidades de conviver com outras crianças da mesma faixa etária possibilita o estímulo às suas capacidades interativas e o desenvolvimento da competência social, fornecendo modelos de interação e evitando o isolamento contínuo (CAMARGO; BOSA, 2012, p. 316).

Entretanto, a inclusão escolar de estudantes com autismo não deve estar centrada somente na ideia de fornecer esses contatos sociais - que favorecem não só o seu desenvolvimento, mas o das outras crianças, na medida em que aprendem com as diferenças - mas, devem pretender o desenvolvimento de uma série de outras habilidades cognitivas. Assim sendo, o PC, em um contexto inclusivo, deve estar ciente de que "[...] todo plano de formação deve servir para que os professores se tornem aptos ao ensino de toda a demanda escolar [...] seu conhecimento deve ultrapassar a aceitação de que a classe comum é, [...] um mero espaço de socialização" (MANTOAN, 2001, p. 60).

Somente o PC5 citou a aprendizagem como fator predominante para a socialização, destacando a importância do atendimento pedagógico especializado no contraturno. Contudo, percebe-se que, ainda que implicitamente, persiste uma visão desse atendimento como substitutivo e 
não complementar ao ensino regular.

Esta criança [autista] poderia estar, no contraturno, frequentando uma escola, ou melhor, uma sala com mais recursos, com pessoas que tenham mais condições de trabalhar com ela. Porém, a escola regular é fundamental para que essa criança venha a se socializar, para que ela possa também adquirir novos conhecimentos e, ao mesmo tempo, contribuir para o crescimento das outras pessoas (PC5, 2015).

Cumpre saber que PC1 e PC3 destacaram ainda a importância de atendimentos com equipes multidisciplinares, neste caso, estabelecendo um trabalho paralelo ao da Unidade Escolar, porém, colaborativo com os educadores

[...] a criança deve ter atendimentos, as instâncias da saúde têm que estar atendendo ele paralelamente à educação (PC1, 2015).

Eu acho que deveria ter psicólogo, um acompanhamento de psicólogo paralelo ao da escola, somado aos relatórios dos professores, para a verdadeira inclusão (PC3, 2015).

Essas concepções são reforçadas pela Política Nacional de Educação Especial na Perspectiva da Educação Inclusiva (BRASIL, 2008, p. 13), que recomenda uma ampla parceria e a construção de uma sólida rede de apoio aos sistemas inclusivos.

Para assegurar a intersetorialidade na implementação das políticas públicas a formação deve contemplar conhecimentos de gestão de sistema educacional inclusivo, tendo em vista o desenvolvimento de projetos em parceria com outras áreas, visando à acessibilidade arquitetônica, aos atendimentos de saúde, à promoção de ações de assistência social, trabalho e justiça.

Embora afirmem acreditar que a inclusão no ensino regular seja a alternativa de atendimento mais adequada aos estudantes com autismo, os PC entrevistados destacaram dificuldades práticas na execução dessa política pública, tais como a ausência de suporte pedagógico, informação e formação nesta área, apontando estas como causadoras de inseguranças e até mesmo preconceitos entre os professores.

Eu não discordo da inclusão, mas tem professor que... Eu tenho sentido muito na pele, é... Agora até que diminuiu bastante [...] mas o professor reclama muito da questão de não estar capacitado para isso, não é? Mas é mais medo (PC1, 2015).

Eu acredito que deva ter mais formação para os professores e mais informação, porque ainda tem muito preconceito [...] Parte dos professores ainda tem também muito preconceito, não preconceito por aceitação, mas o preconceito por não conhecimento (PC2, 2015). 
Porque às vezes é uma coisa até simples, mas pela falta de conhecimento se torna uma coisa muito complexa! É difícil, às vezes a gente fala: Nossa, o que é que eu faço? Porque não tenho suporte, não é? Mas, mesmo não sendo a nossa especialidade, temos que trabalhar com todos! (PC3, 2015).

Essas barreiras também podem ser consideradas frutos da ausência de uma formação de professores, inicial e continuada, numa perspectiva de educação inclusiva. Nessa perspectiva, persiste a necessidade de rever a concepção da formação pedagógica, superando os delineamentos clínicos e reabilitadores, bem como orientando os professores a partir de enfoques mais interativos do processo de aprendizagem, para as diretrizes educacionais e curriculares do ensino regular (AINSCOW; BLANCO, 1997 apud BRUNO, 2007).

\section{Relação entre escola e família}

Tratando-se do relacionamento entre a escola e a família dos estudantes com autismo, todos os entrevistados afirmaram ser a parceria um elemento primordial, enfatizando ainda a necessidade do fortalecimento do elo de confiança e apoio mútuo entre ambas as instâncias sociais. O relato dos PC2, PC3 e PC4 trazem essa confirmação.

Primeiro: a família tem que entender que a escola não é inimiga! Nós somos parceiros! Nós precisamos deles [os pais] e eles precisam da gente, porque o estudante tem que ser o nosso público alvo [...] Eles precisam sentir na gente a segurança de que o filho deles não vai ser excluído. Eles precisam sentir na gente que há uma aceitação, um respeito (PC2, 2015).

Eu acho essencial! A escola tem que ir atrás dos pais, dessa parceria... E eu acho que pra qualquer um, não só pro autismo, porque qualquer diagnóstico, qualquer informação contribui, ajuda em um relatório, ajuda se precisar de um apoio específico em algum assunto... Eu acho que tem que estar junto, não só do estudante especial, mas pra qualquer estudante, essa é uma relação essencial! Não tem como: a gente tem que falar a mesma língua, saber como está em casa, como é o desenvolvimento na escola (PC3, 2015). A gente tem que ter um relacionamento muito aberto com os pais, de diálogo, nós precisamos muito da ajuda deles (PC4, 2015).

Santos (1999 apud UCHÔA, 2015) corrobora essas colocações, ressaltando que

[...] a participação da família é de suma importância no movimento da inclusão. Seja de forma individualizada ou por meio de organizações, é imprescindível a sua participação para que a continuidade histórica da luta por sociedades mais justas para seus filhos seja garantida. É importante a sua participação, pois a família irá exercer a sua cidadania e funcionará como um veículo por meio do qual seus filhos possam aprender a ser (SANTOS, 1999 apud UCHÔA, 2015, p. 31). 
Foram citados como fatores relacionados à família e que geram dificuldades para a plena inclusão do autista no ensino regular, primeiramente, a insegurança sentida pelos pais com relação à escolarização de seus filhos. O relato de PC2 mostra isso.

Muitas vezes tem o preconceito, eles [os pais] acham que se for diagnosticado que o estudante tem autismo, nós vamos excluí-los. Então as mães têm esse receio, de pensar: "Se meu filho tiver autismo, ele vai ser excluído na escola" e isso, às vezes, gera a não aceitação [...] A família se assusta: "O meu filho vai ser "o diferente" da sala", "Meu filho vai ser "o excluído"! (PC2, 2015).

Considerando que, segundo Silva (2003 apud CÉLIO SOBRINHO; ALVES, 2013), os pais consideram o corpo docente como o principal interlocutor da relação família e escola, pode-se concluir que o acolhimento e intervenção pedagógica do professor frente ao estudante com autismo influencia sobremaneira a visão do pai com relação à inclusão escolar de seu filho, gerando assim a segurança/insegurança dos mesmos.

Em um segundo momento, os entrevistados citam como elementos dificultadores o distanciamento familiar do acompanhamento escolar, bem como a negligência de informações sobre o estudante com autismo. O PC5 e o PC3 relatam esse fato.

Geralmente quando a criança está nos anos iniciais, há um melhor acompanhamento por parte das famílias, porém, quando as crianças vão ficando mais velhas e vão para os anos finais e médio, a gente vê esse distanciamento. Aí começa, tanto a escola quanto a família, um a culpar o outro, quando na verdade teria que ter um trabalho coletivo né? Porque o objetivo maior tem que ser ajudar a criança (PC5, 2015).

Também tem que sentir como é com a família! Se não tiver esse contato, de falar: "Pai, como foi no médico? Tem documentação?". O nosso relatório também é feito a partir dessa documentação, das informações que o pai trás, senão eu acho que a gente vai só prejudicar o estudante, vai perder tempo! O pai tem que estar presente e também a escola tem que se amparar, se o pai não der esse feedback, a escola também tem que relatar, porque senão fica como se a gente tivesse culpa também, deixando a desejar em alguma coisa que a gente poderia estar ajudando (PC3, 2015).

Apesar das dificuldades apresentadas, é evidente a necessidade de superar os obstáculos, em busca da efetivação de uma parceria sólida entre família e profissionais envolvidos no ambiente escolar. Dessa forma, "[...] a família seria mais bem informada em relação aos seus direitos, responsabilidades e recursos [...]. No caso dos profissionais, estes poderiam adquirir mais conhecimento sobre as características positivas e as necessidades da família e da criança" (SILVA, 2007, p. 20). 


\section{Papel do professor coordenador frente à inclusão de estudantes com}

\section{autismo}

A abordagem a respeito do papel do PC frente à inclusão dos estudantes com autismo centrou-se apenas em uma vertente: a formação de professores. Esse fator é extremamente relevante, já que indica o envolvimento e comprometimento dos entrevistados com suas atribuições, sobretudo, a de "orientar o trabalho dos demais docentes, nas reuniões pedagógicas e no horário de trabalho coletivo [...]", bem como assegurar "a participação proativa de todos os professores [...], promovendo situações de orientação sobre práticas docentes de acompanhamento e avaliação das propostas de trabalho programadas" (SÃO PAULO, 2014, Art. 5ํ). Em consonância com essas ideias, apresenta-se a análise da PC1 e do PC5 sobre o papel do PC mediante a inclusão do estudante com autismo.

\footnotetext{
O que a gente pode fazer, enquanto coordenador é contribuir nas formações, nas ATPC, e depois acompanhar e dar suporte para o professor fazer o seu trabalho em sala de aula... E também buscar atendimentos, as instâncias da saúde têm que estar atendendo ele [o estudante autista] paralelamente, eu acredito (PC1, 2015).

A gente tem obrigação de ajudar como coordenador, não é? Trabalhando este assunto nas próprias formações de ATPC, procurando alguns materiais que podem estar nos auxiliando a mostrar para o professor que ele é capaz de trabalhar com essas crianças, que ele não está sozinho... [...] A nossa função é estar ali, em parceria com o professor e procurando mecanismos, meios que possam estar ajudando a sua prática (PC5, 2015).
}

Percebe-se que esses PC já compreendem a formação continuada em educação inclusiva como um processo que envolve reflexão e mudanças de postura, mas também ação e acompanhamento em sala de aula, além da busca por outros apoios e suportes - internos e externos que se fizerem necessários. Nessa perspectiva, Lima e Cavalcante $(2009$, p. 8) afirmam que "A formação na inclusão não fornece respostas prontas, não é uma múltipla habilitação para atendimento a todas as dificuldades possíveis em sala de aula, mas é uma formação que trabalha o olhar do educador sobre seu estudante [...]".

Em um discurso de similaridade e complementaridade, a PC3 apresenta suas concepções sobre o apoio do PC ao professor, enfatizando ainda a necessidade de considerar o repertório de cada docente na troca de experiências durante as formações, além da construção de um plano de atendimento às necessidades individuais do estudante com autismo. 
Eu poderia auxiliar com as orientações para o professor, elaborando ATPC voltadas para o tema, pesquisando e trazendo pra eles vídeos, materiais para lermos e discutirmos... Eles também poderiam trazer contribuições sobre o tema, dividirmos o assunto, trocarmos experiências nesta área. Depois, é preciso verificar o rendimento do estudante na sala de aula, também o comportamento dele com os colegas, não só na sala de aula, mas na escola, em todas as atividades: recreio, Educação Física, em tudo! Só depois desse diagnóstico inicial, poderíamos criar um plano de trabalho, indicando de onde partir e se vamos precisar ir atrás de ajuda, de outros encaminhamentos e apoios (PC3, 2015).

Corroborando com essa concepção, Lima e Cavalcante (2009) propõem

A criação de espaços para a formação contínua do professor no seu cotidiano escolar, por meio do diálogo, discussão e debates e do conhecimento implícito que os atores internos e externos desenvolvem no espaço escolar e fora dele podem ser uma possibilidade, um foco irradiador para a reconstrução do projeto político-pedagógico da escola e da educação, da construção de uma escola aberta para todos (LIMA; CAVALCANTE, 2009, p. $11)$.

Todavia, essa visão ampla do processo formativo não mostrou ser um consenso do grupo de entrevistados, fator que pode ser percebido na análise da resposta dada, primeiramente, pela PC2.

Primeiro, acho que temos que conhecer a família do estudante, ver se a família tem aceitação ou não! Daí, tentar conscientizar o professor, em ATPC, de que tem que trabalhar com esses estudantes, mostrar que ele tem que dar atenção... Porque tudo que esses estudantes precisam é de carinho, se ele [o autista] ver que é excluído, ele vai se afastando... Então, é importante conscientizar os professores [...] (PC2, 2015).

Pode-se perceber que, embora a PC2 reconheça a importância da formação continuada como ferramenta de conscientização e superação das barreiras invisíveis, tais como rótulos, estigmas e preconceitos, há em sua fala um reducionismo do processo inclusivo, traduzindo-se na necessidade de um atendimento pedagógico somente focado no carinho e na atenção. Essa perspectiva afasta a construção do entendimento da escola inclusiva, ou seja, um espaço onde todos têm direito e são capazes de aprender, e acaba reforçando a hipótese de que os estudantes com autismo incluídos no ensino regular só terão benefícios nos aspectos sociais.

Na sequência, a PC4 apresenta suas ideias.

Eu nunca tive um estudante com autismo e nunca fiz nenhum curso sobre isso, então acho difícil poder ajudar... Eu acredito que eu só teria condições se eu fosse preparada antes, participasse de uma capacitação! Mas, se não 
tivesse condições e eu soubesse que iria receber um estudante assim, eu iria estudar um pouquinho sobre o autismo né? Para passar pros professores... Fazendo algum curso, acho que teria mais sucesso (PC4, 2015).

Por fim, embora tenham algumas divergências entre si, já apresentadas aqui, todos os cinco entrevistados têm um ponto em comum quando se trata da formação continuada em educação inclusiva: só se iniciam as discussões quando há, de fato, um estudante com autismo ou com deficiência matriculado em sua Unidade Escolar. Percebe-se assim que ainda não há uma cultura inclusiva nas escolas: ao invés de se estabelecer uma prática formativa que vise o atendimento de todos os estudantes, inclusive público-alvo da Educação Especial, se continua desenvolvendo ações isoladas e ocasionais, na tentativa de instrumentalizar o professor para lidar especificamente com as deficiências ou transtornos. Diferente dessa prática, em uma perspectiva inclusiva

[...] a formação vai além dos aspectos instrumentais, pois há o exercício constante de reflexão, do questionamento da própria prática em busca de caminhos pedagógicos da inclusão e, ainda, de ações das experiências concretas que são a matéria prima para a mudança [...] (LIMA; CAVALCANTE, 2009, p.10).

\section{Considerações Finais}

A partir deste estudo percebeu-se que os professores coordenadores atuantes nos anos iniciais do ensino fundamental aqui entrevistados possuem conhecimento a respeito da definição de autismo, contudo, enfatizam as limitações apresentadas pelos mesmos como não passíveis de evolução ou, até mesmo, em alguns momentos, voluntárias. Essa visão, tida como clínica e "medicalizada", que talvez se dê em virtude do difícil e contraditório processo de construção conceitual de autismo influencia nas concepções pedagógicas desses profissionais sobre os estudantes com autismo: percebe-se uma ênfase demasiada nas dificuldades e problemas, e pouca crença nas possibilidades e potencialidades. Assim sendo, os mesmos não demonstram possuir uma visão integrada do estudante, como uma pessoa completa e capaz de aprender, mas sim a percepção de um diagnóstico que se sobrepõe ao indivíduo, tardando assim a construção de uma perspectiva inclusiva no ambiente escolar.

Essa concepção se reflete diretamente na relação com as famílias que, por vezes, se mostram inseguras e distantes, por não acreditarem na escolarização de seus filhos, com base nos comportamentos e afirmações dos próprios professores e também da equipe gestora, mas sobretudo no processo de formação continuada dos professores. Embora reconheçam a formação continuada 
como ferramenta principal de apoio à inclusão do estudante com autismo, os PC entrevistados ainda a enxergam como um processo instrumentalizador e técnico e, desta forma, centram-se somente nas definições do que é o autismo, sem dar continuidade a este processo de construção de valores inclusivos nos demais âmbitos e conteúdos curriculares, independente de possuir ou não um estudante com autismo matriculado em suas Unidades Escolares.

Fica claro, assim, que há a urgência na implementação de uma política pública sistematizada e concreta de formação continuada destinada aos PC, visando uma mudança significativa de valores em uma perspectiva inclusiva, para que se possa atingir o professor em sala de aula. É preciso que o próprio PC se sinta seguro e capaz em suas atuações, o que só será possível com base em uma formação sólida e contínua no que se refere não só a concepções e definições, mas também a procedimentos e práticas pedagógicas inclusivas. Sob essa ótica, o PC necessita tanto de refletir sobre conteúdos, métodos e técnicas de ensino para a formação dos estudantes quanto se preparar para subsidiar a prática cotidiana de seus professores durante a ação pedagógica em sala de aula.

Somente estando em constante formação é que o professor coordenador conduzirá o processo formativo nas escolas possibilitando que seus professores intervenham pedagogicamente mediante as mais diversas diferenças, entre elas, os estudantes com autismo que tenham sido inseridos no processo educativo regular. Dessa forma, conquista-se o que de fato vem a ser a inclusão.

\section{Referências}

AMERICAN PSYCHIATRIC ASSOCIATION. Manual diagnóstico e estatístico de transtornos mentais: DSM-5. Tradução Maria Inês Corrêa Nascimento et al. 5. ed. Porto Alegre: Artmed, 2014.

BARDIN, L. Análise de conteúdo. Tradução Augusto Pinheiro e Luís Antero Reto. São Paulo: Edições 70, 2011.

BELISÁRIO FILHO, J. F.; CUNHA, P. A Educação Especial na Perspectiva da Inclusão Escolar: Transtornos Globais do Desenvolvimento. Vol. 9 (Coleção A Educação Especial na Perspectiva da Inclusão Escolar). Brasília: Ministério da Educação, Secretaria de Educação Especial; [Fortaleza]: Universidade Federal do Ceará, 2010.

BERETA, M. S.; VIANA, P. B. M. Os benefícios da inclusão de alunos com deficiência em escolas regulares. Revista Pós Graduação: Desafios Contemporâneos. Cachoeirinha, v. 1, n. 1, p. 115-129, jun. 2014.

BRASIL. MEC. Secretaria de Educação Fundamental. Parâmetros Curriculares Nacionais: adaptações curriculares. Brasília: MEC/ SEF/ SEESP, 1999.

Política Nacional de Educação Especial na Perspectiva da Educação Inclusiva. Brasília: Ministério da Educação e Cultura. Secretaria de Educação Continuada, Alfabetização, Diversidade e 
Inclusão,

2008.

Disponível

em:

http://portal.mec.gov.br/index.php?option=com docman\&view=download\&alias=16690-politicanacional-de-educacao-especial-na-perspectiva-da-educacao-inclusiva-05122014\&ltemid=30192.

Acesso em: 26 jan. 2016.

Lei no 12.764, de 27 de dezembro de 2012. Brasília: 2012. Disponível em: http://www.planalto.gov.br/ccivil 03/ ato2011-2014/2012/lei//12764.htm. Acesso em: 30 out. 2017.

BRUNO, M. M. G. Educação Inclusiva: Componente da Formação de Educadores. Revista Benjamin Constant. São Paulo, ano 13, n. 38, dez. 2007. Disponível em: http://www.ibc.gov.br/media/common/Nossos Meios RBC RevDez2007 Artigo 2.doc. Acesso em: 10 jan. 2016.

CAMARGO, S. P. H. Competência social, inclusão escolar e autismo: um estudo de caso comparativo. 2007. 91f. Dissertação (Mestrado em Psicologia) - Instituto de Psicologia, Universidade Federal do Rio Grande do Sul, Rio Grande do Sul, 2007. Disponível em: http://www.msmidia.com/pospsico/producao2.asp?orientador=Cleonice\%20Bosa. Acesso em: 28 out. 2017.

CAMARGO, S. P. H.; BOSA, C. A. Competência Social, Inclusão Escolar e Autismo: um estudo de caso comparativo. Revista Psicologia: Teoria e Pesquisa. Brasília, v. 28, n. 13, jul/set. 2012. Disponível em: http://www.scielo.br/pdf/ptp/v28n3/a07v28n3.pdf. Acesso em: 29 out. 2017.

CÉLIO SOBRINHO, R.; ALVES, E. P. A Relação entre Família e Escola em um Contexto de Escolarização do Aluno com Deficiência: reflexões desde uma abordagem sociológica figuracional. Educar em Revista, Curitiba, n. 49, p. 323-338, jul/set., 2013. Disponível em: http://www.scielo.br/pdf/er/n49/a18n49.pdf. Acesso em: 30 out. 2017.

DUK, C. (Org.). Educar na Diversidade: material de formação docente. 3. ed. Brasília: Ministério da Educação, Secretaria de Educação Especial, 2006. Disponível em: http://portal.mec.gov.br/seesp/arquivos/pdf/educarnadiversidade2006.pdf. Acesso em: 29 out. 2017.

GADOTTI, M. O projeto político-pedagógico da escola na perspectiva de uma educação para a cidadania. Nota de palestra, São Paulo: 2001. Disponível em: http://gadotti.org.br:8080/xmlui/bitstream/handle/123456789/457/AMG PUB 03 026.pdf?sequen ce=1\&isAllowed=y. Acesso em: 29 out. 2017.

LAGO, M. Autismo na Escola: ação e reflexão do professor. 2007. 170f. Dissertação (Mestrado em Educação) - Universidade Federal do Rio Grande do Sul, Porto Alegre, 2007. Disponível em: http://www.lume.ufrgs.br/bitstream/handle/10183/13077/000638908.pdf. Acesso em: 29 out. 2017.

LIMA, H. S.; CAVALCANTE, T. C. F. A Formação Continuada do Professor para Educação Inclusiva na Rede Municipal do Recife. Pernambuco, 2009. Disponível em: http://docplayer.com.br/10509912-Aformacao-continuada-do-professor-para-educacao-inclusiva-na-rede-municipal-do-reciferesumo.html. Acesso em: 13 dez. 2015.

LOPES, J. C. A Formação de Professores para a Inclusão Escolar de Estudantes Autistas: contribuições psicopedagógicas. 2011. 44f. Trabalho de Conclusão de Curso (Especialização em Psicopedagogia Clínica e Institucional) - Instituto de Psicologia - Departamento de Psicologia Escolar e do Desenvolvimento - Universidade de Brasília, Brasília, 2011. Disponível em: http://bdm.unb.br/bitstream/10483/3523/1/2011 \%20JulianaCrespoLopes.pdf. Acesso em: 29 out. 2017. 
MANZINI, E. J. Considerações sobre a elaboração de roteiro para entrevista semi-estruturada. In: MARQUEZINE, M. C.; ALMEIDA, M. A.; OMOTE, S. (Orgs.), Colóquios sobre pesquisa em Educação Especial. Londrina: Eduel, 2003. p. 11-25.

MANTOAN, M. T. E. Integração x Inclusão: Escola (de qualidade) para Todos. Núcleo Temático: Escola, Diversidade e Inclusão. Programa de Apoio Didático. Universidade de Campinas, São Paulo, 2001. Disponível em: <http://www.lite.fe.unicamp.br/cursos/nt/ta1.9.htm>. Acesso em: 10 jan. 2016.

PAULA, J. Inclusão: mais que um desafio escolar, um desafio social. São Paulo: Jairo de Paula Editora, 2004.

SÃO PAULO (Estado). Resolução SE 88, de 19 de dezembro de 2007. Disponível em: <http://www. siau.edunet.sp.gov.br/ItemLise/arquivos/88 07.htm>. Acesso em: 28 jun. 2015.

Resolução SE 61, de 11 de novembro de 2014. Disponível em: http://siau.edunet.sp.gov.br/ItemLise/arquivos/61 14.HTM?Time=04/05/2015\%202. Acesso em: 30 out. 2017.

Resolução SE 75, de 30 de dezembro de 2014. Disponível em: http://siau.edunet.sp.gov.br/ItemLise/arquivos/75 14.HTM?Time=30/10/2017\%2021:59:31. Acesso em: 12 jan. 2016.

SERRA, D. C. G. A inclusão de uma criança com autismo na escola regular: desafios e processos. 2004. 110f. Dissertação (Mestrado em Educação) - Centro de Ciências e Humanidades, Universidade do Estado do Rio de Janeiro, Rio de Janeiro, 2004. Disponível em: http://www.proped.pro.br/teses/teses pdf/DISSERTAO\%20Dayse\%20Carla\%20G.\%20Serra.pdf. Acesso em: 28 out 2017.

SILVA, A. M. Buscando componentes da parceria colaborativa na escola entre famílias de crianças com deficiência e profissionais. 2007. 122f. Dissertação (Mestrado em Educação Especial) - Centro de Educação e Ciências Humanas, Universidade São Carlos, São Carlos. Disponível em: https://repositorio.ufscar.br/bitstream/handle/ufscar/2957/1272.pdf?sequence=1. Acesso em: 30 out. 2017.

UCHÔA, Y. F. A Criança Autista na Educação Infantil: desafios e possibilidades na educação inclusiva. 2015. 40f. Trabalho de Conclusão de Curso (Graduação em Pedagogia) - Universidade Estadual da Paraíba, Centro de Educação, 2015.2 Disponível em: http://dspace.bc.uepb.edu.br/jspui/bitstream/123456789/7959/1/PDF\%20\%20Yasmim\%20Figueiredo\%20Uch\%C3\%B4a.pdf. Acesso em: 13 jan. 2016.

Recebido em: 24/08/2017

Aceito em: 31/10/2017 